\title{
Sobre a noção de causalidade em Hume e Malebranche
}

\author{
CARLOTA SALGADINHO FERREIRA *
}

* Doutoranda em Filosofia
pela PUC-Rio
Bolsista CAPES

\begin{abstract}
RESUMO Uma certa noção do princípio da não-contradição e um ponto de partida particular de David Hume (1711-1777) e Nicolas de Malebranche (16381715) tornou os seus sistemas filosóficos muito distintos um do outro, apesar de partilharem alguns aspetos, particularmente a respeito da noção de causalidade. É isto que nos vai permitir distinguir entre i) um ponto de vista no qual temos acesso claro à verdade e no qual entendemos que a necessidade que atribuímos aos objetos é uma falsa (e injustificada) necessidade, e ii) outro ponto de vista, no qual estamos imersos e sob a influência do qual somos levados a postular essa necessidade.
\end{abstract}

PALAVRAS-Chave Ocasionalismo; Causalidade; Malebranche; Hume.

NA ePISTEmologia de Hume (que afirmou, ele mesmo, ter-se debruçado sobre a obra de Malebranche quando escreveu o Tratado da Natureza Humana, em 1737, numa carta a um amigo ${ }^{1}$ destrói-se o fundamento de certas noções, como é o caso de Deus ou da existência exterior (cuja demonstração, no caso da primeira, e prova, no caso da segunda, Malebranche expõe n'A busca da verdade), não havendo qualquer garantia teórica de um substrato para as perceções. Isso deve-se ao ponto de partida de Hume, a saber, i) o de que não podem existir ideias na mente sem que tenha havido experiência. A par disso, ii) a existência das impressões é inegável e, por conseguinte, se há algum conhecimento infalível, é o da experiência proporcionada pelas impressões. Esse é o único que não podemos negar, com relação às questões de facto. Aliás, há que notar que i), que é o ponto de partida de Hume, só constitui um verdadeiro fundamento de toda a sua arquitetura conceptual se acrescentarmos ii). Caso contrário, poder-se-ia

1 NADLER, Malebranche on Causation, p. 133. 
facilmente alegar que a imaginação também é uma fonte efetiva (e por isso, válida) de ideias, para além dos sentidos: esta premissa tem um caráter tão factual quanto a de que os sentidos são fonte de ideias.

É impossível avaliar a herança de Hume relativamente a Malebranche, no tocante à teoria da causalidade, sem ter como um dos eixos da problematização desta questão o facto de a existência de Deus, para Malebranche, ser objeto de demonstração. A distinção entre as suas conceções assenta, em parte, numa diferença quanto às possibilidades teóricas de um conhecimento sobre a existência de Deus.

Do lado de Hume, devido ao facto de que o conhecimento do qual podemos estar mais seguros ser o dos sentidos e à aplicação de um critério de necessidade lógico (às relações de ideias e às questões de facto; vê-lo-emos em seguida), torna-se impossível qualquer demonstração e justificação para a crença na existência de objetos que jamais são presentes aos nossos sentidos, o que vale, por conseguinte, para Deus ${ }^{2}$. Deste modo, Hume jamais poderia considerar uma via alternativa pela qual pudéssemos encontrar uma verdadeira causalidade, (aquela que satisfaz o princípio da não-contradição) num objeto exterior. Tal é permitido a Malebranche, porque este parte de pressupostos cartesianos: o ego reificado, o estatuto das ideias (do entendimento) e do conhecimento dos sentidos e, por fim, a demonstração da existência de Deus, no qual aquele encontra a dita garantia para a correção dos raciocínios causais. De facto, mesmo remetendo para uma causalidade maior, entre os objetos há uma conexão necessária (que Deus realizou porque quis) ${ }^{3}$.

A relação causal é encarada por Malebranche como uma conexão necessária entre dois eventos, tal que é indiferente o que ocorre (como presumível efeito) quando a causa não ocorre e que, dada a ocorrência da causa, é impossível que o (presumível) efeito não ocorra, portanto, é impossível o caso em que a causa ocorre e o efeito não ocorre. Tal significa que a ocorrência da causa nos obriga a inferir ou esperar a ocorrência do efeito. Outra forma de descrever a relação causal, que é, aliás, a forma como Malebranche e Hume a descrevem, é a que introduz o dito critério de necessidade lógica aos objetos

$2 T, 1.4 \cdot 5$.

3 Como também nota Kail (cf. Hume, Malebranche and Rationalism, p. 316), este é talvez o ponto mais importante que separa os autores, pelo menos considerando a primordialidade que tem em cada um dos seus sistemas. 
presentes à mente. Uma relação entre objetos, factos, acontecimentos é necessária se não conseguimos conceber o contrário da ocorrência de ambos sem contradição ${ }^{4}$. Se aquilo que julgamos ser a causa de um evento ou facto é a sua verdadeira causa, então o contrário da ocorrência do efeito (a sua não ocorrência) é inconcebível por nós sem que se contradiga, de alguma forma, a causa ou a sua ocorrência. Assim, se estamos perante uma verdadeira causa (conexão necessária, não esqueçamos), concebendo a ocorrência do efeito, não podemos não conceber a ocorrência do efeito e, igualmente, contradiremos a causa se concebermos o contrário da ocorrência do efeito (a sua não ocorrência). Esta definição tem um caráter lógico: o princípio da não-contradição é o que confere uma condição de possibilidade e inteligibilidade à relação causal.

Para ambos os autores, podemos, de facto, com respeito aos objetos (pretensamente) externos, conceber a ocorrência da causa sem uma obrigação teórica de conceber a ocorrência do efeito. Tal é sinal de que a conexão necessária atribuída aos factos observáveis, dos quais temos ideias e sobre os quais raciocinamos, não se refere a uma verdadeira causalidade.

No caso de Hume, tal deve-se ao caráter atómico das perceções (que, por sua vez, se deve ao chamado princípio da cópia). Aplicando-se o critério da não-contradição às questões de facto, vemos que o contrário de uma questão de facto é sempre concebível (pelo pensamento ou imaginação) sem contradição com aquela e, por isso, é possível. Por seu turno, aquilo cujo contrário não é concebível sem contradição é necessário (como é o caso, por exemplo, de 2+2 não são 4). Este critério é utilizado para distinguir os dois tipos de conhecimento possíveis: demonstração e probabilidade, o primeiro dos quais se detém das ideias que estão conformes ao princípio da não-contradição, e o segundo, às ideias que respeitam impressões, que não caem sob a sua alçada.

Por seu turno, para Malebranche, a impossibilidade de conceber a causa sem conceber o efeito apenas se dá, especificamente, relativamente à criação do mundo de acordo com a vontade de Deus. Tal como para Descartes, também para Malebranche a criação divina é um ato livres . Como tal, ele não pode estar determinado ou obrigado

4 BV, p. 246.

5 BV, p. 277; MCM, p. 79-83. É importante notar também que a criação supõe um conhecimento. A falta de conhecimento que temos de todos os meios para executar uma ação (por exemplo, todos 
a criar o mundo. Por isso, o facto de o mundo ter sido criado não é necessário, mas contingente: conceber a vontade livre de Deus não nos obriga a conceber a criação do mundo. Por outro lado, a ordem natural que ele efetivamente estabeleceu não é necessária, no sentido em que ele podia ter querido criar outra ordem causal, sem que isso contradiga a natureza livre da sua vontade ${ }^{6}$. O que não pode acontecer é que uma vez que Deus tenha querido criar um mundo e lhe dar uma certa ordem, essa vontade não se cumpra, pois que isso contradiria a natureza omnipotente de Deus. O contrário acontece com o homem. Por isso, a necessidade que define a verdadeira causalidade tem de estar associada à realização de uma vontade (neste caso, uma vontade que não pode ser contrariada).

Apesar de Deus poder não ter querido criar o mundo, uma vez que ele o queira, é impossível que ele não realize a sua vontade. Aí reside a verdadeira necessidade do seu poder causal. Não devemos dar atenção ao facto de que a criação do mundo é, de alguma forma, contingente: isso é necessário, dado que a vontade divina é livre? ${ }^{7}$ Se a criação do mundo não fosse contingente, a sua vontade seria condicionada (e não omnipotente, como é o caso).

Nesse sentido, a causalidade entre os factos observáveis no mundo resulta de um engano da nossa mente, ao pretendermos que a conexão que estabelecemos entre eles tem um caráter logicamente necessário, e o poder que julgamos identificar entre os objetos é, na verdade, um poder que só Deus possui. Cada relação causal que se pode estabelecer é apenas uma ocasião $0^{8}$ da concretização da vontade divina, única à qual jamais se pode negar uma potência ativa e um conhecimento que permitam o exercício de um poder de mover, trazer à existência.

É importante distinguir entre uma necessidade lógica e psicológica do critério de aceitabilidade da relação causal. Ele tem um caráter lógico porque se aceita que a sujeição à não-contradição é o que confere inteligibilidade à noção de causa, ditando as nossas

os processos biológicos envolvidos no ato de levantar um braço), assim como dos objetos para agirem uns sobre os outros, prova, para Malebranche, que as causas naturais ou segundas são causas ocasionais, e não verdadeiras.

6 Não pretendemos presentemente discutir a questão das verdades eternas.

7 MCM, p. 246.

8 BV, p. 245-7. 
(im) possibilidades de conceção e de raciocínio. Por outro lado, essa sujeição é algo que se verifica por um exercício cognitivo. Em boa verdade, podemos dizer que a própria lógica tem um caráter psicológico. Independentemente da conclusão positiva de Malebranche e da conclusão negativa de Hume, o critério para responder à questão de saber se existe uma verdadeira causalidade entre os factos reside na nossa (im) possibilidade de conceber o contrário da ocorrência dos factos sem contradição.

Mas este caráter psicológico entra em jogo noutro sentido. Para Hume, há um segundo sentido de necessidade, que supõe já a admissão do estabelecimento de relações causais, apesar do reconhecimento do seu caráter falível, segundo o qual se pode admitir como necessário o que é observado constante e uniformemente. Julgamos justo admitir, uma vez que Hume não o refere explicitamente, que as crenças na causalidade, num eu unívoco e na existência exterior são tão frequentes e enraizadas na mente que têm um caráter necessário, que é eminentemente psicológico porque se deve à natureza humana, mais especificamente, dos princípios e faculdades mais eminentemente envolvidos na experiência e no raciocínio (é o caso dos princípios de associação, da faculdade da imaginação, das impressões de reflexão ou dos sentidos). Contudo, para Malebranche, uma vez que a conceção das ideias claras é operada em Deus e não nas mentes particulares, o critério assume um caráter divino, já que a obrigação teórica de respeitar a não-contradição é um imperativo da razão, que concebe ideias claras (que estão na mente de Deus).

Podemos admitir que, no caso de Hume, a não-contradição leva a epistemologia a um colapso no ceticismo, uma vez que esse critério nos permite perceber o caráter falível do conhecimento sobre questões de facto, e toda a engrenagem cognitiva que está envolvida na crença na existência exterior.

Com respeito à origem da causalidade e não mais ao seu estatuto metafísico, ambos os autores consideram a relação causal que estabelecemos entre dois objetos (pretensamente exteriores) como resultado da observação da união constante (repetida) desses objetos. À semelhança do erro presente nos juízos dos sentidos ao atribuir (indevidamente) uma exterioridade às qualidades presentes nas nossas sensações (uma relação causal entre os objetos e a nossa mente), para Malebranche, atribuir relações causais entre os objetos (entre si) é um erro que resulta de uma ausência de clareza nas nossas ideias. Se consultarmos a nossa razão, facilmente percebemos que 
a matéria e o espírito não possuem, em si mesmos, uma potência ativa e, mesmo, que tal não seria sequer concebíve19 ${ }^{9}$.

Note-se que ambos os autores consideram que identificamos uma relação causal i) a partir do objeto que julgamos ter o poder sobre outro, que postulamos como sendo seu efeito, quer seja apenas este último ou ambos observados, e ii) a conexão que os objetos (pretensamente) mantêm entre si, que é sempre invisível; Estas são, aliás, as duas definições de causa que Hume oferece ${ }^{10}$. Podemos observar que inclusivamente, o célebre exemplo das bolas de bilhar, que Hume oferece para explicar a sua noção de causalidade, aparece mais que uma vez na obra de Malebranche ${ }^{11}$. Para ambos os autores, os sentidos não nos conduzem (pelo menos, corretamente, para Malebranche, e de todo, para Hume) a essa conclusão, mas é essa a primeira fonte dessa nossa crença. Seguidamente, é a faculdade da imaginação que nos conduz diretamente a ela.

Para Malebranche são vereditos da razão: i) que a atribuição de uma relação causal natural aos objetos entre si é impossível e essa atribuição, que, de facto, fazemos, é uma ficção da imaginação, que apenas nos proporciona uma ideia confusa de causalidade; ii) que, com relação à causalidade autêntica, ela apenas pode ser concebida como criação de uma potência que o objeto não possui; o seu contrário não é concebível por nós, portanto, é impossível; logo, a única causa verdadeira tem de ser Deus, pois só ele é capaz de trazer à existência de um objeto uma potência que este não possuía até então ${ }^{12}$.

Note-se também, apesar disso, que nenhum dos autores inviabiliza uma procura da verdade. Estivéssemos constante e plenamente cientes de que as causas que julgamos necessárias têm, na verdade, um elemento contingente por natureza (a de terem sido, de facto, objeto da vontade divina, em vez de outro possível), ao determinar as relações entre os objetos continuaríamos a estar, certamente, diante de uma verdade universal: as leis divinas são universais, imutáveis, regulares ${ }^{13}$. Pelo contrário, para Hume, uma vez que o conhecimento se fundamenta num critério fenoménico, nenhu-

\footnotetext{
9 BV, p. 324; MCM, p. 81.

$10 \mathrm{~T}, 1.3 .14 \cdot 35$.

11 BV, p. 180, 182; HUME, Investigação sobre o Entendimento Humano, 4.1.8-11; 7.1.6, 21; 7.2.28, 30.

$12 B V$, p. 327, 329-30.

13 MCM, p. 78.
} 
ma prova ${ }^{14}$ pode garantir que exista uma verdade por trás da regularidade observável, como seu substrato objetivo. Portanto, resta, para Hume, a tarefa de explicar o porquê de se postular essa relação e, posteriormente, constatar a regularidade com que o fazemos e prosseguir os estudos da Ciência do Homem mediante este novo critério ${ }^{15}$.

Para Hume, a relação de causalidade entre os objetos é, sob os critérios da razão demonstrativa, injustificada, pois que as impressões são entidades atómicas, e o futuro pode sempre ser contraditório com o passado. A repetição e o exercício do hábito sobre a faculdade da imaginação, mais o exercício dos seus princípios (semelhança, contiguidade e causalidade) produzem a crença (mesmo no caso da prova), uma forte inclinação da mente para esperar o acontecimento dos factos conforme uma determinada hipótese, entre outras possíveis, que fora inúmeras vezes experienciada e associada na imaginação.

Note-se que, com Hume, o critério de inteligibilidade das ideias não ultrapassa as capacidades da mente humana nem o próprio homem: não há um referencial divino ao qual remeter uma maior inteligibilidade, nem uma localização das ideias, como em Malebranche e, de resto, no cartesianismo. Porém, Hume apresenta regras para corrigir, por assim dizer, o entendimento (interpretado como a faculdade da imaginação no exercício

$14 T, 1.3 .11 .2$. Hume aceita como válida a distinção entre conhecimento (demonstração) e probabilidade (raciocínios causais). Mas, no caso da prova, há milhares de experiências de um mesmo acontecimento (de uma determinada relação de causa-efeito) e nenhuma do seu contrário. Nesse caso, jamais aceitamos que a nossa expectativa para o futuro (semelhante ao passado) se reduza a uma probabilidade. Por isso, uma designação tripartida é mais explícita: conhecimento para a demonstração, absolutamente certa, prova para os argumentos causais, livres de incerteza, e probabilidade, para os mesmos raciocínios, mas que é sempre acompanhada de incerteza (as duas últimas respeitantes a questões de facto e a primeira, às relações entre ideias). Neste trabalho não nos concentraremos na análise da distinção entre prova e probabilidade, pois o que aqui mais importa é a origem ou fonte de ambos enquanto referentes a questões de facto. Quer na prova, quer na probabilidade, a origem da necessidade da conexão entre os objetos é a observação e a associação entre ideias por parte dos princípios da faculdade da imaginação e o hábito. Há uma continuidade no que toca aos objetos: eles são do mesmo tipo. A diferença reside na diversidade das experiências e das causas (no primeiro caso, apenas uma, no segundo caso, de várias causas concorrentes). $\mathrm{O}$ relacionamento entre ideias é exatamente do mesmo tipo nos dois casos. Mas, como a experiência que resulta nas provas é mais uniforme, a crença é mais firme e enraizada do que a crença que resulta de uma experiência diversa. Kemp Smith (em The Philosophy of David Hume) aborda, também, esta definição.

15 Aliás, o único possível para as questões de facto, enquanto objetos de uma experiência na nossa mente; jamais poderíamos exigir que fosse de outro modo, pois que as impressões serão sempre entidades atómicas. 
dos seus princípios mais regulares e necessários). Estas regras devem “filtrar” a experiência de acordo com a sua frequência e semelhança, de instância para instância, a fim de não se caia no preconceito e se julgue, tanto quanto possível, de acordo com a maior probabilidade que se nos apresenta. Trata-se de pôr de lado a tarefa do fundamento ou, se se quiser, de fornecer um fundamento fraco para o conhecimento das questões de facto, aquele que depende da cumulatividade da experiência. A noção de necessidade assente na não-contradição não lhe é aplicável, pois que o fenomenalismo é inescapável: nunca teremos a certeza se o conhecimento científico descobre as leis universais dos fenómenos ou se estas não passam de construções nossas, sem um referente objetivo e independente de nós. Ainda assim, é possível estebelecer um guia para os raciocínios envolvidos nas várias práticas científicas (essas regras) ${ }^{16}$.

Concluindo, parece que para ambos os autores (e apesar das suas muitas diferenças), o fundamento para o conhecimento instaura uma separação radical entre as ordens do conhecimento e da vida pragmática (pois que a crença da imaginação não é inevitável), já que a razão constata que essas duas ordens se contradizem. No entanto, a ordem da natureza aparece-nos com uma certa configuração, que nos é dada pela experiência (configuração que, apesar disso, é fruto da imaginação e, portanto, injustificada assim que se ultrapassa a simples efetividade da experiência). Porém, uma vez que essas crenças da imaginação são necessárias (do ponto de vista psicológico), o estudo dos factos é operado pelo entendimento, que forja crenças se não lógica, pelo menos pragmática ou factualmente apoiadas, em questões de facto, e é possível um conhecimento probabilísitico justificado por um segundo (porém, mais fraco) critério de verdade e correção.

$16 T, 1.3 .15$. 


\section{REFERÊNCIAS BIBLIOGRÁFICAS}

HUME, D. (1739-40). Tratado da Natureza Humana. Trad. João Paulo Monteiro. Lisboa: Fundação Calouste Gulbenkian, 2012 [T]

(1748). Investigação sobre o entendimento humano. Trad. João Paulo Monteiro. Lisboa: Imprensa Nacional Casa da Moeda, 2002

KAIL, P. Hume, Malebranche and Rationalism. Philosophy, vol. 83, n. 3, 2008, pp. 311-332

MALEBRANCHE, N. (1683). Meditações Cristãs e Metafísicas. Trad. Adelino Cardoso. Lisboa: Colibri, 2003 [MCM]

(1674-75). A busca da verdade. Trad. Plínio Junqueira Smith. São Paulo: Discurso Editorial: Paulus, 2004 [BV]

NADLER, S. Malebranche on Causation, in Cambridge Companion to Malebranche. Ed. Steven Nadler. Cambridge, Cambridge University Press, 2000 